\title{
Real-time PCR using FRET technology for Old World cutaneous leishmaniasis species differentiation
}

Milli Nath-Chowdhury ${ }^{1}$, Mugundhine Sangaralingam', Patrick Bastien², Christophe Ravel ${ }^{2}$, Francine Pratlong ${ }^{2}$, Juan Mendez ${ }^{3}$, Michael Libman ${ }^{1,4}$ and Momar Ndao ${ }^{1,4^{*}}$

\begin{abstract}
Background: Recently, there has been a re-emergence of cutaneous leishmaniasis in endemic countries and an increase in imported cases in non-endemic countries by travelers, workers, expatriates, immigrants, and military force personnel. Old World cutaneous leishmaniasis is caused primarily by Leishmania major, L. tropica and L. aethiopica. Despite their low sensitivity, diagnosis traditionally includes microscopic and histopathological examinations, and in vitro cultivation. Several conventional PCR techniques have been developed for species identification, which are time-consuming and labour-intensive. Real-time PCR using SYBR green dye, although provides rapid detection, may generate false positive signals. Therefore, a rapid and easy method such as a FRET-based real-time PCR would improve not only the turn-around time of diagnosing Old World cutaneous Leishmania species but will also increase its specificity and sensitivity.
\end{abstract}

Methods: A FRET-based real-time PCR assay which amplifies the cathepsin L-like cysteine protease B gene encoding a major Leishmania antigen was developed to differentiate L. major, L. tropica, and L. aethiopica in one single step using one set of primers and probes. Assay performance was tested on cutaneous and visceral strains of Leishmania parasite cultures and isolates of other protozoan parasites as well as human biopsy specimen.

Results: The assay readily differentiates between the three Old World cutaneous leishmaniasis species based on their melting curve characteristics. A single Tm at $55.2 \pm 0.5^{\circ} \mathrm{C}$ for L. aethiopica strains was distinguished from a single $\mathrm{Tm}$ at $57.4 \pm 0.2^{\circ} \mathrm{C}$ for L. major strains. A double curve with melting peaks at $66.6 \pm 0.1^{\circ} \mathrm{C}$ and $48.1 \pm 0.5^{\circ} \mathrm{C}$ or $55.8 \pm 0.6{ }^{\circ} \mathrm{C}$ was observed for all L. tropica strains. The assay was further tested on biopsy specimens, which showed $100 \%$ agreement with results obtained from isoenzyme electrophoresis and Sanger sequencing.

Conclusion: Currently, there are no published data on real-time PCR using FRET technology to differentiate between Old World cutaneous Leishmania species. In summary, our assay based on specific hybridization addresses the limitations of previous PCR technology and provides a single step, reliable method of species identification and rapid diagnostic applications.

Keywords: qPCR, Real-time PCR, Leishmania, Cutaneous, Diagnosis, FRET, Melting curve

\footnotetext{
* Correspondence: momar.ndao@mcgill.ca

'National Reference Centre for Parasitology, Research Institute of the McGill

University Health Centre, Montreal, QC, Canada

${ }^{4}$ J.D. MacLean Centre for Tropical Diseases at McGill University, Montreal, QC,

Canada

Full list of author information is available at the end of the article
} 


\section{Background}

Leishmaniasis, an infection caused by obligate intramacrophage protozoa transmitted predominantly by the bite of an infected phlebotomine female sandfly is endemic throughout tropical and subtropical regions [1]. Cutaneous leishmaniasis (CL), which is characterised by ulcerative lesions on the skin (localised CL) and nonulcerative nodules (diffuse CL) is endemic in 88 countries with an estimated 1.5-2 million new cases every year and a total of 12 million cases worldwide [2, 3]. There has been a recent re-emergence of this disease in endemic countries and an increase in imported cases in non-endemic countries where travelers, workers, expatriates, immigrants, and military force personnel have been the main victims [2, 4-6]. CL is amongst the top ten diseases in tourists returning from tropical countries with skin problems [2, 7]. Old World CL (OWCL), prevalent in southern Europe, Mediterranean basin, Africa and the Middle-East is caused primarily by Leishmania major, L. tropica and L. aethiopica [4, 8], although CL cases due to $L$. donovani and $L$. infantum strains have also been reported $[9,10]$.

Diagnosis of CL traditionally includes microscopic examination of Giemsa-stained biopsy smears or tissue aspirates, histopathological examination, and in vitro cultivation. These methods however, in spite of their high specificity, are poorly sensitive and their sensitivity largely depends on the sampling procedure, parasite distribution and ad hoc expertise. Serological assays such as Enzyme-linked Immunosorbent Assay (ELISA), indirect fluorescence antibody test (IFAT) and western blot (WB) are preferred for the diagnosis of visceral leishmaniasis (VL) rather than CL due to the low titre of circulating antibodies against the parasite and cross-reactivity with other antigens (e.g. Trypanosoma cruzi) [11].

Molecular diagnostic methods such as PCR are the current preferred method of diagnosis due to their high specificity, sensitivity (98-100\%) and speed [12, 13]. Identification of the parasite at the species level is often crucial for epidemiological studies, transmission control measures, disease prognosis and choice of treatment $[14,15]$. Before the advent of PCR protocols, the species of Leishmania was determined by enzyme-based assays such as Multi Locus Enzyme Typing (MLET) which were both time-consuming and labour-intensive. Several PCR-based techniques have been developed for species identification that require post-PCR processing such as electrophoretic analysis, PCR-restriction fragment length polymorphism (PCR-RFLP), PCR-ELISA and sequencing [16-19].

Real-time PCR not only allows the accurate detection and quantification of specific DNA in real time but also allows species identification without the requirement of post-PCR processing. Samples can be processed in less than one hour and the technique has been reported to rapidly differentiate single nucleotide mutations within a target DNA sequence [20]. To date, real-time PCR using SYBR green dye I has been reported several times for species discrimination [14, 21-24]. However, this method detects all amplified double-stranded DNA, including non-specific reaction products and can thereby generate false positive signals [25]. Recently, probe-based real-time PCR using Fluorescence Resonance Energy Transfer (FRET) identifies and distinguishes between New World tegumentary Leishmania species in clinical samples based on melting curve profiles with high specificity [26] thereby eliminating false positives.

Different PCR primers have been developed or applied for the detection and/or identification of Leishmania species [27]. One gene of interest, the $c p b$ gene, encodes for cathepsin L-like cysteine proteinase B $(c p b)$, a major antigen of Leishmania parasites and is conserved among the Leishmania species [28]. Its polymorphic and multicopy nature presents an excellent opportunity for the development of species specific and sensitive primers [29]. Currently, separate primer sets targeting the $c p b$ gene are needed to identify the OWCL species using conventional PCR, therefore requiring post-PCR processing [27] and this technique has demonstrated a lack of sensitivity in clinical samples [30].

In the present study, we describe a real-time PCR assay using FRET technology that is based on the amplification of the cathepsin L-like cysteine protease B $(c p b)$ gene, to differentiate the main OWCL species: L. major, L. tropica, and L. aethiopica, in cultured parasite isolates and biopsy specimens. Currently, there are no published data on real-time PCR using FRET technology to differentiate between these OWCL species. This FRET-based real-time PCR assay requires specific hybridization between the probe and its target to generate a fluorescent signal thereby addressing the limitations of the SYBR green technology and providing a rapid, single step, reliable method of species identification for OWCL.

\section{Methods}

\section{Ethics statement}

Samples were obtained from multiple reference laboratories including the Canadian National Reference Centre for Parasitology/J.D. MacLean Centre for Tropical Diseases at McGill University (Montreal, QC), Centre Hospitalier Régional Universitaire of Montpellier and University Montpellier I (Montpellier, France) and Walter Reed Army Institute of Research (Silver Spring, Maryland) and were considered exempt. All samples used in this study were anonymized.

\section{Leishmania reference strain samples}

DNA from L. major, L. tropica, and L. aethiopica promastigotes and cryopreserved promastigote cultures of 
various Leishmania reference strains were provided by the International Biological Resources Center for Leishmania, affiliated to the French National Reference Center for Leishmanioses, University Hospital Center of Montpellier, France. Additional DNA from L. aethiopica strains (promastigote stage) was provided by the Walter Reed Army Institute of Research, USA. An overview of all strains used is presented in Table 1 .

\section{Cutaneous lesion specimens}

Cutaneous biopsy specimens which were sent to the National Reference Center for Parasitology between 2005 and 2006 for Leishmania testing, and were found to be positive in culture and by conventional PCR [31], were used to validate the real-time PCR assay. These biopsy culture isolates were also species typed by isoenzyme electrophoresis at the Walter Reed Army Institute of Research, USA. An overview of the specimens used is presented in Table 1.

\section{Cell culture and DNA extraction}

Cryopreserved promastigotes and patient skin biopsies suspected of being positive for Leishmania were cultivated in vitro at $27^{\circ} \mathrm{C}$ in RPMI 1640 medium (Wisent, St-Bruno, QC) supplemented with $20 \%$ fetal bovine serum, non-essential amino acids (Wisent, St-Bruno, QC), MEM amino acids (Wisent), $1 \mathrm{mM}$ sodium pyruvate, $2 \mathrm{mg} / \mathrm{ml}$ dextrose, $2 \mathrm{mM}$ L-glutamine, $100 \mathrm{u} / \mathrm{ml}$ penicillin/streptomycin, and $25 \mathrm{mM}$ HEPES. A set of control DNA standards from cultured promastigotes was prepared to determine the sensitivity of the realtime PCR. Promastigotes of L. major, L. tropica and $L$. aethiopica were suspended in PBS and uninfected human blood, counted in a Neubauer hemacytometer (Hausser Scientific, Horsham, PA) and diluted at a concentration of $10^{6}$ parasites $/ 200 \mu$ l. Ten-fold dilutions were made to $10^{-2}$ parasites $/ 200 \mu \mathrm{l}$. DNA was extracted from the promastigote dilutions and directly from patient skin biopsies using the QIAamp DNA Mini Kit (QIAGEN, Hilden, Germany) according to the manufacturer's instructions. Following centrifugation and washing steps, DNA was eluted from the spin columns in $200 \mu \mathrm{l}$ elution buffer and stored at $-20{ }^{\circ} \mathrm{C}$ until use. Similarly, non-leishmanial protozoan DNA was extracted from blood specimen positive for Plasmodium species, Trypanosoma cruzi and Trypanosoma brucei, and from parasite cultures of Toxoplasma gondii RH strain (courtesy of Gary E. Ward, University of Vermont), Giardia lamblia ATCC 30957 (courtesy of Gaetan Faubert, Institute of Parasitology, Quebec), Cryptosporidium parvum Iowa strain (courtesy of Michael Arrowood, Center for Disease Control) and Entamoeba histolytica ATCC 30015.

\section{Primer and probe design}

Consensus primers and probes, designed by TIBMol Biological (New Jersey, USA), were based on the alignment of $c p b$ sequences for L. major (GenBank: AJ512654), L. tropica (GenBank: DQ286773) and L. aethiopica (GenBank: DQ071678). Alignment was done using ClustalW2 (v2.0.12, European Bioinformatics Institute, http://www.ebi.ac.uk). By comparing the $c p b$ sequences of $L$. major, L. tropica and $L$. aethiopica, oligonucleotides were designed such that the FRET hybridization assay could selectively amplify DNA from each species, but allow for differences on melting curve temperature $(\mathrm{Tm})$ analysis. The $c p b$ sequence was almost identical for L. tropica and L. aethiopica with $96 \%$ similarity. $L$. major $c p b$ sequence shared $92 \%$ similarity with that of $L$. tropica and $91 \%$ similarity with that of $L$. aethiopica. A single primer and probe set was designed to amplify specimens from the OWCL species (Fig. 1a). Probes were designed to be specific for L. tropica and identify a single base-pair mismatch in L. major and two base-pair mismatches in L. aethiopica. The forward primer contains one wobble base to identify adenosine in the $c p b$ gene of $L$. aethiopica and $L$. major as well as guanine in $L$. tropica $c p b$ gene. Primers and probes (Table 2) were aligned with OWCL species and with those causing visceral and mucocutaneous forms (Fig. 1b).

\section{FRET-based real-time PCR}

Real-time PCR reactions were performed using the Light Cycler Fast Start DNA Master HybProbe kit (Roche, Mannheim, Germany) and contained $2 \mu \mathrm{l}$ of $10 \times$ Master Mix, $5 \mathrm{mM}$ final $\mathrm{MgCl}_{2}$ concentration, $0.2 \mu \mathrm{M}$ of each probe, $0.5 \mu \mathrm{M}$ of each primer, and $2 \mu \mathrm{l}$ of template DNA in a final volume of $20 \mu \mathrm{l}$. Real-time PCR cycling was performed on the Light Cycler 1.5 (Roche) with amplification at $95{ }^{\circ} \mathrm{C}$ for $10 \mathrm{~min}$ followed by 40 cycles of $95^{\circ} \mathrm{C}$ for $5 \mathrm{~s}, 53{ }^{\circ} \mathrm{C}$ for $8 \mathrm{~s}$, and $72{ }^{\circ} \mathrm{C}$ for $9 \mathrm{~s}$, with single fluorescence acquisition at the end of each annealing step. Amplification was followed by a melting program of $95^{\circ} \mathrm{C}$ for $20 \mathrm{~s}, 40{ }^{\circ} \mathrm{C}$ for $20 \mathrm{~s}$, and a final increase to $85^{\circ} \mathrm{C}$ at the rate of $0.2^{\circ} \mathrm{C} / \mathrm{s}$ with continuous fluorescence acquisition. To ensure the reproducibility of the assay, DNA from reference strains (L. major MHOM/IL/81/Friedlin, L. tropica $\mathrm{MHOM} / \mathrm{IQ} / 65 / \mathrm{L} 75$, and L. aethiopica MHOM/ET/96/ WR2315) were included as positive controls in each run. An uninfected human DNA sample and a water sample were included as negative template and non-template controls respectively in each run.

\section{Direct sequencing and analysis}

In order to ensure primer specificity and for validation, PCR products amplified from both promastigote and cutaneous biopsy DNA were subjected to agarose gel 
Table 1 Overview of Leishmania strains used

\begin{tabular}{|c|c|c|c|c|}
\hline Species & Strain & $\begin{array}{l}\text { Parasite } \\
\text { culture }\end{array}$ & Biopsy & Provider \\
\hline \multirow[t]{8}{*}{ L. aethiopica } & MHOM/ET/96/WR2315 & No & No & WRAIR \\
\hline & MHOM/SD/99/WR2885a & No & No & WRAIR \\
\hline & $\begin{array}{l}\text { MHOM/PH/2010/ } \\
\text { WR2970 }\end{array}$ & No & No & WRAIR \\
\hline & MHOM/ET/83/130-83c & No & No & FNRCL \\
\hline & MHOM/ET/90/DISKOC & No & No & FNRCL \\
\hline & MHOM/ET/70/L96 ${ }^{C}$ & No & No & FNRCL \\
\hline & MHOM/ET/81/1091-81 ${ }^{\mathrm{C}}$ & No & No & FNRCL \\
\hline & MPRV/ET/71/L111 ${ }^{c}$ & No & No & FNRCL \\
\hline \multirow[t]{9}{*}{ L. tropica } & MHOM/IQ/65/L75 & Yes & No & FNRCL \\
\hline & MHOM/SU/74/K27 & Yes & No & FNRCL \\
\hline & I000/IL/98/LRC-L757 & Yes & No & FNRCL \\
\hline & MHOM/AF/06/NRCP2559 & Yes & Yes & $\mathrm{NRCP}$ \\
\hline & MHOM/AF/05/NRCP358 & Yes & Yes & $\mathrm{NRCP}$ \\
\hline & MHOM/SU/66/III & No & No & FNRCL \\
\hline & MHOM/KE/91/EB135 & No & No & FNRCL \\
\hline & MHOM/MA/95/LEM3015 & No & No & FNRCL \\
\hline & MHOM/IR/2000/LEM4036 & No & No & FNRCL \\
\hline \multirow[t]{11}{*}{ L. major } & MHOM/IL/81/Friedlin & Yes & No & NRCP \\
\hline & MHOM/DZ/05/NRCP684 & Yes & Yes & NRCP \\
\hline & MHOM/BF/06/NRCP2082 ${ }^{\mathrm{b}}$ & Yes & Yes & NRCP \\
\hline & $\mathrm{MHOM} / \mathrm{BF} / 06 / \mathrm{NRCP} 2204^{\mathrm{b}}$ & Yes & Yes & NRCP \\
\hline & MHOM/TN/06/NRCP248b & Yes & Yes & $\mathrm{NRCP}$ \\
\hline & MHOM/BZ/05/NRCP2620 & Yes & Yes & NRCP \\
\hline & MRHO/SU/59/P-STRAIN ${ }^{c}$ & No & No & FNRCL \\
\hline & MHOM/SU/73/29-ASKH ${ }^{c}$ & No & No & FNRCL \\
\hline & MHOM/IL/83/IL24 & No & No & FNRCL \\
\hline & MTAT/KE/00/T4 ${ }^{c}$ & No & No & FNRCL \\
\hline & MHOM/DZ/89/LIPA228 & No & No & FNRCL \\
\hline L. chagasi & MHOM/BR/74/M2682 & Yes & No & FNRCL \\
\hline \multirow[t]{2}{*}{ L. infantum } & MHOM/TN/80/IPT1 & Yes & No & FNRCL \\
\hline & MHOM/MA/67/ITMAP263 & Yes & No & FNRCL \\
\hline \multirow[t]{5}{*}{ L. donovani } & MHOM/IN/80/DD8 & Yes & No & FNRCL \\
\hline & MHOM/KE/55/LRC-L53 & Yes & No & FNRCL \\
\hline & MHOM/IQ/77/BUMM3 & Yes & No & FNRCL \\
\hline & MHOM/YE/86/LEM934 & Yes & No & FNRCL \\
\hline & MHOM/SD/90/2828 & Yes & No & FNRCL \\
\hline \multirow[t]{2}{*}{ L. mexicana } & MHOM/BZ/82/BEL21 & Yes & No & FNRCL \\
\hline & MNYC/BZ/62/M379 & Yes & No & FNRCL \\
\hline $\begin{array}{l}\text { L. } \\
\text { panamensis }\end{array}$ & MHOM/PA/71/LS94 & Yes & No & FNRCL \\
\hline L. guyanensis & MHOM/GF/79/LEM85 & Yes & No & FNRCL \\
\hline \multirow[t]{2}{*}{ L. peruviana } & MHOM/PE//84/UN56 & Yes & No & FNRCL \\
\hline & MHOM/PE/84/LC39 & Yes & No & FNRCL \\
\hline
\end{tabular}

Table 1 Overview of Leishmania strains used (Continued)

\begin{tabular}{cllll}
\hline L. braziliensis & MHOM/PE/90/AC & Yes & No & FNRCL \\
& MHOM/CO/90/UA482 & Yes & No & FNRCL \\
MHOM/BR/75/M2904 & Yes & No & FNRCL \\
MHOM/BR/75/M2903b & Yes & No & FNRCL \\
\hline
\end{tabular}

WRAIR Walter Reed Army of Institute of Research, USA

NRCP National Reference Centre for Parasitology, Canada

FNRCL French National Reference Center for Leishmanioses, France

aDNA samples were provided by WRAIR

${ }^{\mathrm{b}}$ DNA was extracted directly from patient biopsies

'DNA samples were provided by FNRCL

For all other strains, DNA was extracted directly from parasite

electrophoresis containing ethidium bromide and visualized under ultraviolet light. The band of interest was purified with QIAquick Gel Extraction Kit (QIAGEN, Hilden, Germany) and sent for direct Sanger sequencing to the McGill University and Génome Québec Innovation Centre, Montreal, Canada. Sequencing of samples was performed with $\mathrm{cpb} F$ and $\mathrm{cpb} \mathrm{R}$ primers. The quality of the sequences were evaluated and edited with Geneious software (version 9.0.4 - restricted access) and the Leishmania species were identified by BLASTm accessible at Genbank (http://blast. ncbi.nlm.nih.gov/Blast.cgi). The sequences were subsequently aligned with the primers and probes using Jalview software (version 2.9.0b2 - restricted access).

\section{Results}

\section{Species-specific FRET-based real-time PCR}

Using the FRET hybridization approach, species-specific real-time PCRs were performed on 28 DNA samples isolated from promastigote cultures of $L$. tropica, L. aethiopica and L. major reference strains. A species-specific amplicon with $\mathrm{cpb} F$ and $\mathrm{cpb} \mathrm{R}$ primers was visualized in all L. tropica, L. aethiopica, and L. major strains. Melting curve analysis was able to differentiate between the species. A single Tm at $55.2 \pm 0.5^{\circ} \mathrm{C}$ for L. aethiopica strains was distinguished from a single Tm at $57.4 \pm 0.2^{\circ} \mathrm{C}$ for $L$. major strains. A double curve with a melting peak at $66.6 \pm 0.1{ }^{\circ} \mathrm{C}$ and a peak at either $48.1 \pm 0.5^{\circ} \mathrm{C}$ or $55.8 \pm$ $0.6^{\circ} \mathrm{C}$ was observed for all L. tropica strains (Fig. 2).

The sensitivity of the real-time PCR was tested using serial dilutions of parasite DNA extracted from a known number of parasites. The $c p b$ DNA of $L$. major, $L$. tropica and $L$. aethiopica could be detected at a level corresponding to 0.01 parasite per reaction volume of $20 \mu \mathrm{l}$. The detection limit was $10^{-1}$ parasite $/ 200 \mu$ l of human blood, taking into account the amount of biological sample used in the reaction $(2 \mu$ of sample DNA) and the elution volume of the extracted DNA (200 ul).

\section{Non-species-specific real-time PCR}

The specificity of the technique was validated using DNA from 18 strains of Leishmania causing mucocutaneous and visceral leishmaniasis from both the Old and New 


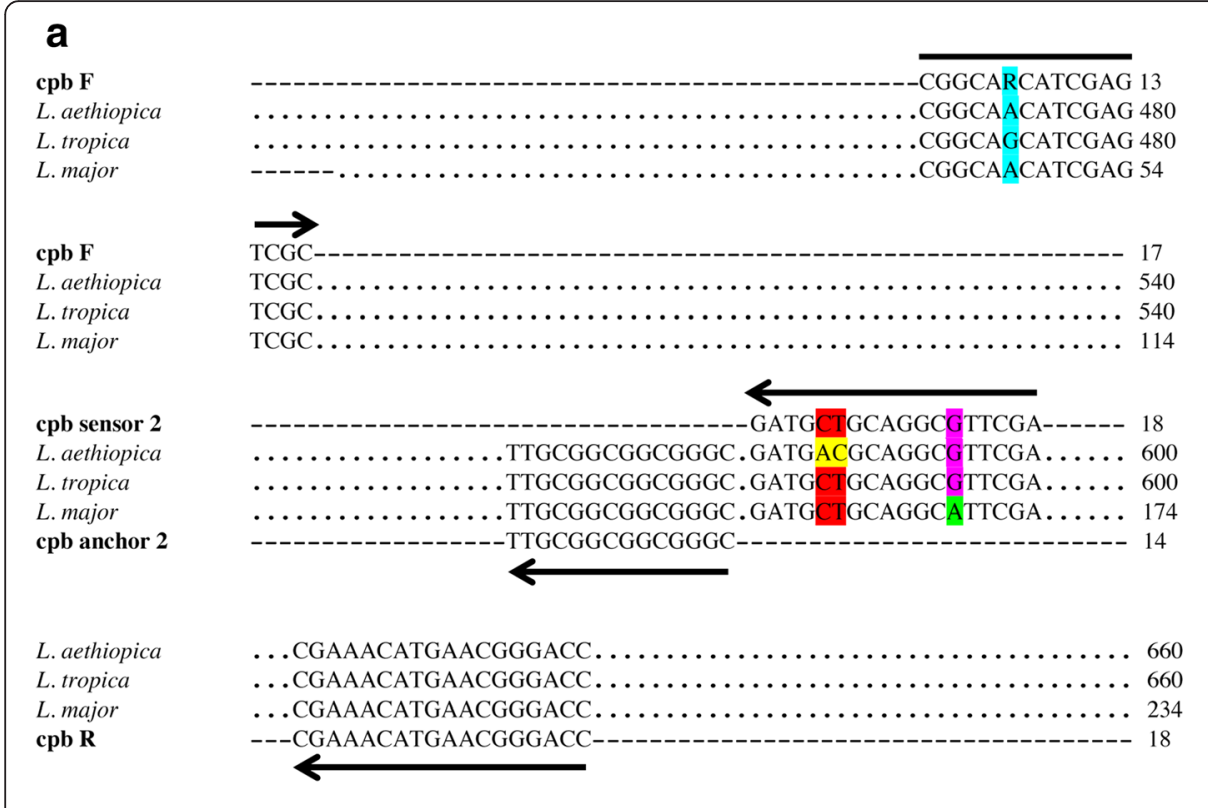

b

cobf

cobanchor2

cobsensor.

CPBR A 1212654

Laethiopica_DQ071678

Linfantum_JN40013?

Loonovani_GQ302673

LChagasi_Af 217087

Larexicana_AJ319727
Lguyanensis_GQ180933

Loanamensis_EU289030

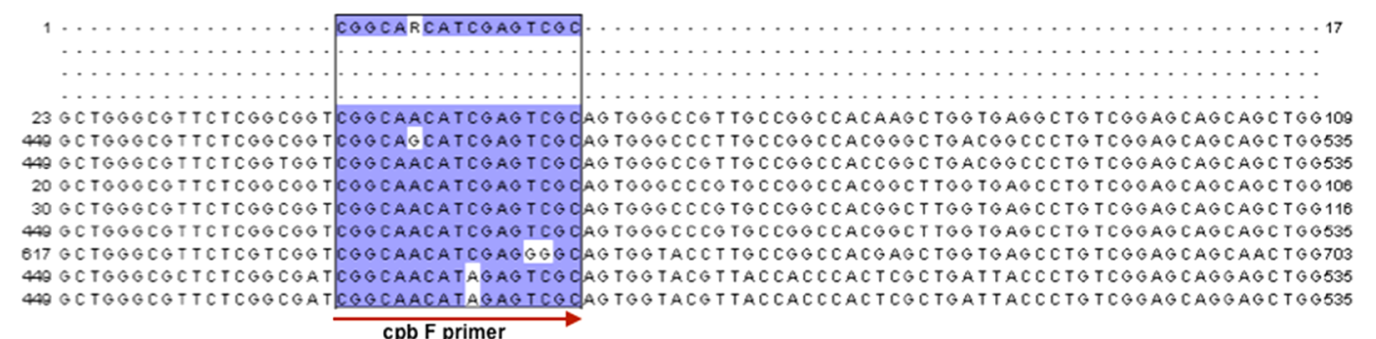

cobs

cobanchorz

cobsensor?

$C P B R$

LmPSOCAN512654

Ltropica_DQ286773

Laethiogica_DQ071678

Linfantum_JiN40013?

Lodonovani_GQ302673

LChagasi_Af 217087

Lurexicana_AJ319727

Lguyanensis_GQ180933

Loanamensis_EU289030

Fig. 1 a Primer and fluorescence probe positions selected for FRET-based real-time PCR of Leishmania cathepsin L-like cysteine protease B gene. Sequences of forward ( $\mathrm{cpb} F$ ) and reverse ( $\mathrm{cpb}$ R) primers were aligned with the corresponding target sequences. Forward primer harbors one wobble base $(R=A / G)$. FRET hybridization probes (cpb sensor 2 and cpb anchor 2) were both designed antisense for detection of parasite. Sensor FRET hybridization probe was designed to be specific for cathepsin L-like cysteine protease B gene of L. tropica (GenBank Accession number: DQ286773) with one nucleotide mismatch difference from that of L. major (GenBank Accession number: AJ512654) and two nucleotide mismatch differences from that of L. aethiopica (GenBank Accession number: DQ071678). b Alignment of the OWCL species and species causing visceral and mucocutaneous leishmaniasis. Sequences are colour-coded by percentage identity

World as well as DNA from other protozoan parasites (Table 3). Non-specific low melting peak temperatures of $44.5^{\circ} \mathrm{C}$ was observed for both L. chagasi and L. infantum, and $45.0 \pm 0.7{ }^{\circ} \mathrm{C}$ for $L$. donovani. The primers cpb $\mathrm{F}$ and cpb R had no specificity for DNA from New World Leishmania species and non-leishmanial parasites (Table 3).

We tested the cross-reactivity of our assay by analysing 17 samples known to contain other parasites including
Plasmodium falciparum, P. ovale, P. malariae, P. vivax, Trypanosoma cruzi, Trypanosoma brucei, Toxoplasma gondii, Entamoeba histolytica, Cryptosporidium parvum and Giardia lamblia along with the reference strains $L$. major MHOM/IL/81/Friedlin, L. aethiopica MHOM/ET/ 96/WR2315 and L. tropica MHOM/KE/91/EB135. Final concentrations ranging from $0.08 \mu \mathrm{g} / \mathrm{mL}$ to $6.4 \mu \mathrm{g} / \mathrm{mL}$ were used to assess the specificity of the real-time PCR. 
Table 2 Primers and probes for the simultaneous detection and identification of OWCL species

\begin{tabular}{llll}
\hline & Name & Sequence $\left(5^{\prime} \rightarrow 3^{\prime}\right)$ & Function \\
\hline Primers & $\mathrm{cpb}$ F & CGGCARCATCGAGTCGC & S \\
& $\mathrm{cpb} \mathrm{R}$ & GGTCCCGTCATGTTCG & AS \\
Fluorescent-labeled & $\mathrm{cpb}$ & TCGAACGCCTGCAGCATC_FL & AS \\
probes & sensor 2 & & \\
& $\mathrm{cpb}$ & LC640-GCCCGCCGCCGCA & AS \\
& anchor 2 & A-PH & \\
\hline
\end{tabular}

$S$ sense sequence, $A S$ antisense sequence

Cross-reactivity was ruled out since amplification was only observed in the three reference strains (Fig. 3).

\section{FRET-based real-time PCR on biopsy samples}

We used the FRET hybridization assay on DNA extracted from seven patients found positive for Leishmania by conventional PCR amplification of the 120 bp region of kinetoplast DNA [32]. By melting peak temperature comparison with the reference strains, five of these patients were identified as being infected with L. major and two with L. tropica (Table 1 ). Species identification for these samples was confirmed by isoenzyme analysis at the Walter Reed Army Institute of Research, USA and further confirmed by Sanger sequencing.

\section{Direct sequencing and analysis}

A distinct band of 154 bp was visualized for all L. major, $L$. tropica and $L$. aethiopica strains. Similarly, a band was also seen at $154 \mathrm{bp}$ for all species within the $L$. (L.) donovani complex.

Sequence comparison with available data in the Genbank database confirmed the amplification of the Leishmania $c p b$ gene in all seven DNA biopsy specimen. Specimen positive for $L$. major by FRET real-time PCR showed $100 \%$ identity with several $L$. major $c p b$ gene sequences including those found in isolates from Tunisia (Accession No. JN400175) and those positive for L. tropica showed 99-100 \% identity with several L. tropica $c p b$ gene sequences deposited at the GenBank database.

\section{Discussion}

We describe the development of a FRET-based real-time PCR using primers and probes targeting the $c p b$ gene sequence to detect and identify the OWCL species ( $L$. major, L. tropica and L. aethiopica) in a single step. This assay was able to produce unique, specific, and reproducible melting curves that could distinguish the three OWCL species (Fig. 2). The $c p b$ sequence for each of the three species of interest has a single or double nucleotide difference from each other, allowing a difference of at least $2{ }^{\circ} \mathrm{C}$ between the Tm values, and enabling easy and reproducible distinction during melting curve

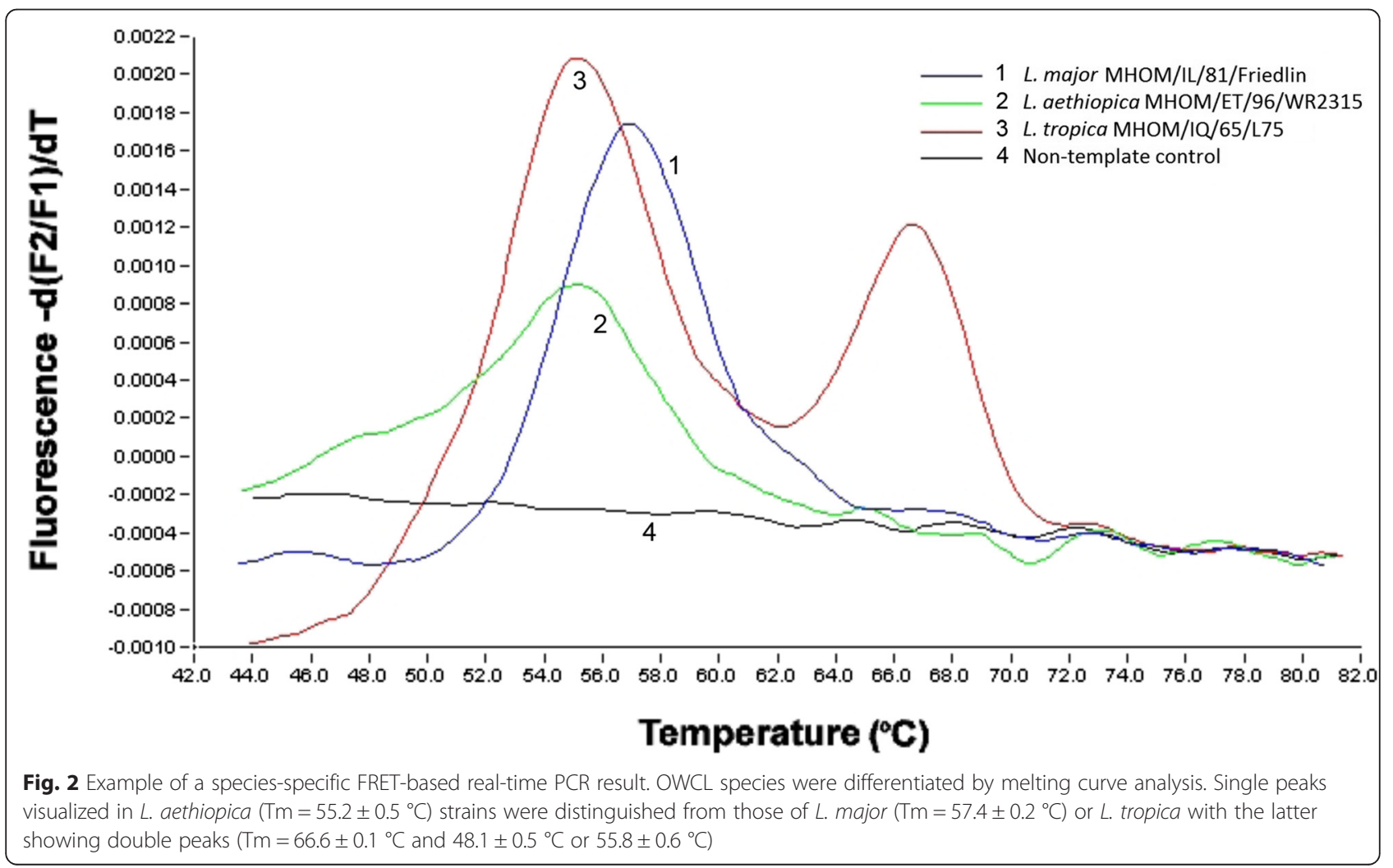


Table 3 Melting curve temperatures obtained from FRET-based real-time PCR assay

\begin{tabular}{|c|c|c|c|}
\hline \multicolumn{4}{|l|}{ Species-specific } \\
\hline Species & Strain & Peak & $\operatorname{Tm}\left({ }^{\circ} \mathrm{C}\right)$ \\
\hline \multirow[t]{8}{*}{ Leishmania aethiopica } & MHOM/ET/96/WR2315 & Single & 54.5 \\
\hline & MHOM/SD/99/WR2885 & Single & 54.5 \\
\hline & MHOM/PH/2010/WR2970 & Single & 55.3 \\
\hline & MHOM/ET/83/130-83 & Single & 55.5 \\
\hline & MHOM/ET/90/DISKO & Single & 55.5 \\
\hline & MHOM/ET/70/L96 & Single & 55.5 \\
\hline & MHOM/ET/81/1091-81 & Single & 55.5 \\
\hline & MPRV/ET/71/L111 & Single & 55.5 \\
\hline \multirow[t]{9}{*}{ L. tropica } & MHOM/IQ/65/L75 & Double & 55.3 | 66.8 \\
\hline & MHOM/SU/74/K27 & Double & 47.5 | 66.5 \\
\hline & I000/IL/98/LRC-L757 & Double & 55.5 | 66.8 \\
\hline & MHOM/AF/06/NRCP2559 & Double & $47.3 \mid 66.5$ \\
\hline & MHOM/AF/05/NRCP358 & Double & 48.5 | 66.5 \\
\hline & MHOM/SU/66/III & Double & 48.5 | 66.5 \\
\hline & MHOM/KE/91/EB135 & Double & 56.5 | 66.5 \\
\hline & MHOM/MA/95/LEM3015 & Double & $48.0 \mid 66.5$ \\
\hline & MHOM/IR/2000/LEM4036 & Double & 48.5 | 66.5 \\
\hline \multirow[t]{11}{*}{ L. major } & MHOM/IL/81/Friedlin & Single & 57.0 \\
\hline & MHOM/DZ/05/NRCP684 & Single & 57.3 \\
\hline & MHOM/BF/06/NRCP2082 & Single & 57.5 \\
\hline & MHOM/BF/06/NRCP2204 & Single & 57.3 \\
\hline & MHOM/TN/06/NRCP248 & Single & 57.3 \\
\hline & MHOM/BZ/05/NRCP2620 & Single & 57.3 \\
\hline & MRHO/SU/59/P-STRAIN & Single & 57.3 \\
\hline & MHOM/SU/73/29-ASKH & Single & 57.5 \\
\hline & MHOM/IL/83/LL24 & Single & 57.5 \\
\hline & MTAT/KE/00/T4 & Single & 57.5 \\
\hline & MHOM/DZ/89/LIPA228 & Single & 57.5 \\
\hline \multicolumn{4}{|c|}{ Non-species specific (causing visceral or mucocutaneous clinical manifestations) } \\
\hline Species & Strain & Peak & $\operatorname{Tm}\left({ }^{\circ} \mathrm{C}\right)$ \\
\hline L. chagasi & MHOM/BR/74/M2682 & Non-specific single & 44.5 \\
\hline \multirow[t]{2}{*}{ L. infantum } & MHOM/TN/80/IPT1 & Non-specific single & 44.5 \\
\hline & MHOM/MA/67/ITMAP263 & Non-specific single & 44.5 \\
\hline \multirow[t]{5}{*}{ L. donovani } & MHOM/IN/80/DD8 & Non-specific single & 45.8 \\
\hline & MHOM/KE/55/LRC-L53 & Non-specific single & 44.5 \\
\hline & MHOM/IQ/77/BUMM3 & Non-specific single & 44.5 \\
\hline & MHOM/YE/86/LEM934 & Non-specific single & 45.8 \\
\hline & MHOM/SD/90/2828 & Non-specific single & 44.5 \\
\hline \multirow[t]{2}{*}{ L. mexicana } & MHOM/BZ/82/BEL21 & None & - \\
\hline & MNYC/BZ/62/M379 & None & - \\
\hline L. panamensis & MHOM/PA/71/LS94 & None & - \\
\hline L. guyanensis & MHOM/GF/79/LEM85 & None & - \\
\hline
\end{tabular}


Table 3 Melting curve temperatures obtained from FRET-based real-time PCR assay (Continued)

\begin{tabular}{|c|c|c|c|}
\hline \multirow[t]{2}{*}{ L. peruviana } & MHOM/PE/84/UN56 & None & - \\
\hline & MHOM/PE/84/LC39 & None & - \\
\hline \multirow[t]{4}{*}{ L. braziliensis } & MHOM/PE/90/AC & Undefined peak & - \\
\hline & MHOM/CO/90/UA482 & None & - \\
\hline & MHOM/BR/75/M2904 & None & - \\
\hline & MHOM/BR/75/M2903b & None & - \\
\hline \multicolumn{4}{|l|}{ Other protozoa } \\
\hline Species & Strain & Peak & $\operatorname{Tm}\left({ }^{\circ} \mathrm{C}\right)$ \\
\hline \multirow[t]{2}{*}{ Plasmodium falciparum } & $10-4881$ & None & - \\
\hline & $10-4830$ & None & - \\
\hline Plasmodium malariae & $10-3066$ & None & - \\
\hline Plasmodium ovale & $10-2848$ & None & - \\
\hline Plasmodium vivax & $99-551$ & None & - \\
\hline \multirow[t]{5}{*}{ Trypanosoma cruzi } & $10-4342$ & None & - \\
\hline & $10-3447$ & None & - \\
\hline & 08-3341 & None & - \\
\hline & $08-2636$ & None & - \\
\hline & $08-2634$ & None & - \\
\hline \multirow[t]{3}{*}{ Trypanosoma brucei } & $09-255$ & None & - \\
\hline & $08-3460$ & None & - \\
\hline & 00-659 (control) & None & - \\
\hline Toxoplasma gondii & RH strain & None & - \\
\hline Entamoeba histolytica & ATCC ${ }^{\circledR} 30015$ & None & - \\
\hline Cryptosporidium parvum & lowa strain & None & - \\
\hline Giardia lamblia & ATCC ${ }^{\circledR} 30957$ & None & - \\
\hline
\end{tabular}

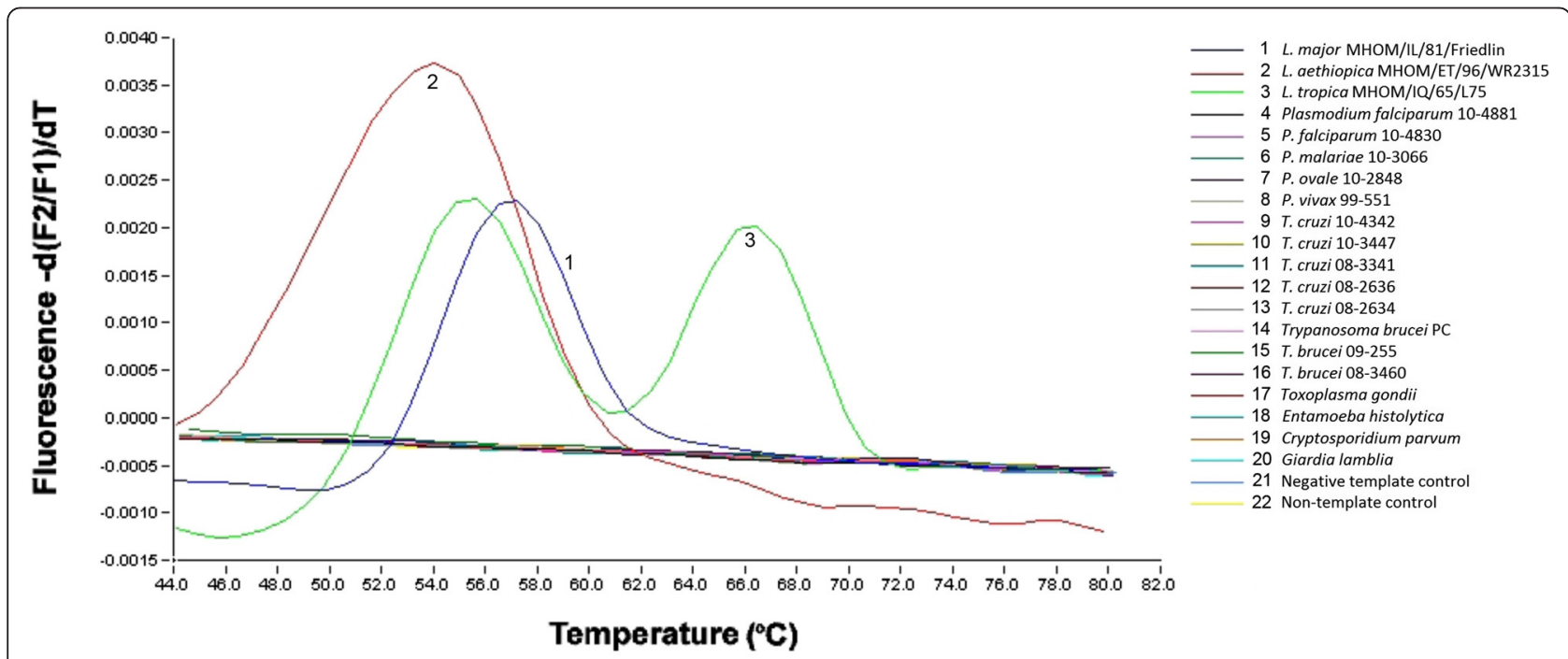

Fig. 3 Cross-reactivity of OWCL FRET-based real-time PCR tested with other protozoa 
analysis. The variation between strains within a single species is minor and did not interfere with the identification of any of the cutaneous strains tested. The Tms for all $L$. major and $L$. aethiopica strains showed standard deviations of only 0.2 and $0.5{ }^{\circ} \mathrm{C}$, respectively.

L. tropica presented a unique bimodal peak with the second peak showing a consistent $\mathrm{Tm}$. The first peak however showed greater $\mathrm{Tm}$ variation. It has been suggested that the first peak could indicate DNA fragments denaturing at lower temperatures such as primer-dimers and non-specific products which usually melt at a lower temperature than desired products [33]. However, all $L$. tropica strains tested showed only one discrete band on the agarose gel. Sequencing results from all $L$. tropica strains showed internal sequence differences. In the past, phylogenetic analysis and Multilocus Enzyme Electrophoresis (MLEE) have revealed genetic diversity and a high degree of allelic heterozygosity within $L$. tropica isolates [34, 35]. These differences may reflect distinct lineages of each strain and may explain the variation in melting characteristics of the first peak. Thus, species differentiation by melting curve analysis can be based on more than a single peak and its associated Tm [36-38]. In our assay, the unique bimodal peak from a single amplicon can be used in the detection and differentiation of $L$. tropica species from other cutaneous species.

Melting curve peaks for visceral species of $L$. chagasi, $L$. infantum and $L$. donovani were visible at $44.8 \pm 0.6^{\circ} \mathrm{C}$. Peaks at low melting point temperatures are usually indicative of either primer-dimers due to their small size or amplification of non-specific products. However, gel results for these species indicate the presence of the target band at $154 \mathrm{bp}$. Although, the presence of a band confirms the identity of the parasite at the genus level, real-time PCR using melting curve analysis would enable species identification. In this case, the presence of a low Tm could be used as a possible marker to differentiate between Leishmania (L.) donovani complex and L. tropica complex. However, a prospective study would be necessary to assess and validate this.

The Tm values for the control reference DNA were highly reproducible on repeated melting curve runs. The melt peaks obtained with our technique are specific for Leishmania species and DNA from other protozoa was not amplified. Other investigators, using melting curve techniques such as high resolution melt analysis, found non-specific amplicons with non-leishmanial DNA although these did not overlap with the Leishmania species [39].

We also tested our FRET-based real-time PCR on seven patient biopsy samples received by the NRCP that were confirmed to be positive for $\mathrm{CL}$ by culture and conventional PCR, and were identified as $L$. major (five samples) and L. tropica (two samples) by the Walter
Reed Army Institute of Research using isoenzyme electrophoresis. The five samples isoenzyme-typed as $L$. major showed $\mathrm{Tm}$ at $57.3 \pm 0.1{ }^{\circ} \mathrm{C}$ and those typed as L. tropica showed double peaks at $\mathrm{Tm} 47.9 \pm 0.9$ and $66.5^{\circ} \mathrm{C}$, thus yielding Tms consistent with our previous results. This highlights the fact that our assay can be performed directly on patient samples without the need for isolation of parasites. We acknowledge that a small number of samples were used in this study. Ideally, this methodology could be further validated using a larger number of strains from a wide variety of sources and geographical areas. A future study conducted on a large sampling of clinical specimen would be necessary to validate this assay on patient DNA. Interestingly, one of the patients (MHOM/BZ/05/NRCP2620) positive for $L$. major in our real-time PCR assay as well in a blind panel for isoenzyme-typing by the Walter Reed Army Institute of Research, had demonstrated travel history to Belize. Given the above results, the presence of $L$. major in Belize comes as a surprise where this specie was not previously reported in this country. It is possible that the patient may have traveled to a Leishmania major endemic country prior to travel to Belize. However, rare cases of $L$. major-like strains have been reported and confirmed in New World countries [40, 41].

Species differentiation by real-time PCR is a highly effective tool in diagnostic laboratories that overcomes the drawbacks of conventional PCR. To date, most real-time PCR assays for cutaneous species differentiation have been developed using the SYBR Green method. Nevertheless, this method has failed to identify or differentiate between some species or requires separate PCRs for each species [14, 21, 23, 42, 43]. Recently, real-time PCRs have been developed in conjunction with FRETbased melting curve analysis for species and genus identification [44-46]. To our knowledge, this FRET-based nested real-time PCR was used to identify New World tegumentary leishmaniasis species targeting the mannose phosphate isomerase gene and the 6-phosphogluconate dehydrogenase gene by melting curve analysis [26]. Using this approach, results can be obtained within a short turnaround time and with relatively low costs.

Whole product melting curve analysis is recommended for species identification because it is more tolerant to small sequence differences that might result from intraspecific variation [47]. For diagnostic purposes, a probebased real-time PCR assay is the preferred method due to its enhanced specificity as well as ease of analysis of the melting curves for species detection and differentiation. Melting curve analysis replaces post-PCR analysis involving nucleotide sequencing followed by comparison to a reference library of Leishmania strains [48].

Kinetoplast DNA, which has often been used as a target due to its high sensitivity in the diagnosis of 
leishmaniasis, can only identify the parasite to the genus or subgenus level [49]. The $c p b$ gene, which has a relatively high copy number and showcases polymorphism between species, appear to give a more reliable species identification. It has been shown previously that the $c p b$ gene could serve as an ideal target to differentiate between the different Leishmania species [29, 30, 45, 50] with a very high sensitivity (100\%) [51]. However, in contrast to previous assays targeting the $c p b$ gene which were only able to distinguish between Leishmania complexes [52] or required multiple PCRs and post-PCR processing $[15,30,45]$, here we developed unique primers that can differentiate between the three OWCL species in a single rapid step.

\section{Conclusion}

In conclusion, we report a new highly sensitive FRETbased real-time PCR that can simultaneously identify the three species of Old World cutaneous leishmaniasis, $L$. aethiopica, L. major and L. tropica, from direct patient samples in a single step that could be used for rapid clinical diagnosis. However, as in any diagnostic procedure, the results of this assay need to be assessed in a routine diagnostic setting in light of the patient's history and symptoms.

\section{Abbreviations}

$\mathrm{CL}$ : cutaneous leishmaniasis; $c p b$ : cysteine proteinase B; FRET: Fluorescence Resonance Energy Transfer; OWCL: Old World CL; Tm: melting curve temperature.

\section{Competing interests}

The authors declare that they have no competing interests.

\section{Authors' contributions}

MNC designed the study, performed the experiments, acquired and analyzed data, and wrote and reviewed the manuscript. MS contributed and reviewed the manuscript. PB provided samples, participated in interpretation of data, reviewed and edited the manuscript. CR and FP provided samples and reviewed the manuscript. JM provided samples, performed the isoenzyme assays and analyses, and reviewed the manuscript. ML reviewed and edited the manuscript. MN supervised and conceived the study, participated in its design, obtained funding and reviewed and edited the manuscript. All authors read and approved the final manuscript.

\section{Acknowledgments}

We thank Loic Talignani and Patrick Lami (University of Montpellier) for their technical assistance with in vitro cultivation of Leishmania strains and with the Leishmania strain database.

The National Reference Centre for Parasitology is supported by Public Health Agency of Canada/National Microbiology Laboratory grant MOA 4500299739, the Foundation of the Montreal General Hospital and the Research Institute of the McGill University Health Centre.

\section{Author details}

${ }^{1}$ National Reference Centre for Parasitology, Research Institute of the McGill University Health Centre, Montreal, QC, Canada. ${ }^{2}$ Department of Parasitology-Mycology, Centre National de Référence des Leishmanioses, Centre Hospitalier Régional Universitaire of Montpellier and University Montpellier I (Faculty of Medicine), UMR CNRS 5290-IRD 224- UM1 et 2 "MIVEGEC", Montpellier, France. ${ }^{3}$ Division of Experimental Therapeutics, Walter Reed Army Institute of Research, Silver Spring, MD, USA. ${ }^{4}$ J.D. MacLean Centre for Tropical Diseases at McGill University, Montreal, QC, Canada.
Received: 22 December 2015 Accepted: 24 April 2016

Published online: 03 May 2016

\section{References}

1. Herwaldt BL. Leishmaniasis. Lancet. 1999;354(9185):1191-9. doi:10.1016/s0140-6736(98)10178-2.

2. Pavli A, Maltezou HC. Leishmaniasis, an emerging infection in travelers. Int J Infect Dis. 2010;14(12):e1032-9. doi:10.1016/j.jij.2010.06.019.

3. Desjeux P. Leishmaniasis: Public health aspects and control. Clin Dermatol. 1996;14(5):417-23. http://dx.doi.org/10.1016/0738-081X(96)00057-0.

4. Antinori S, Gianelli E, Calattini S, Longhi E, Gramiccia M, Corbellino M. Cutaneous leishmaniasis: an increasing threat for travellers. Clin Microbiol Infect. 2005:11(5):343-6. doi:10.1111/j.1469-0691.2004.01046.x.

5. Stark D, van Hal S, Lee R, Marriott D, Harkness J. Leishmaniasis, an emerging imported infection: report of 20 cases from Australia. J Travel Med. 2008;15(5):351-4. doi:10.1111/j.1708-8305.2008.00223.x.

6. Perez-Ayala A, Norman F, Perez-Molina JA, Herrero JM, Monge B, Lopez-Velez R. Imported leishmaniasis: a heterogeneous group of diseases. J Travel Med. 2009;16(6):395-401. doi:10.1111/j.1708-8305.2009.00341.x.

7. Caumes E, Carriere J, Guermonprez G, Bricaire F, Danis M, Gentilini M. Dermatoses associated with travel to tropical countries: a prospective study of the diagnosis and management of 269 patients presenting to a tropical disease unit. Clin Infect Dis. 1995;20(3):542-8.

8. González U, Pinart M, Reveiz L, Alvar J. Interventions for Old World cutaneous leishmaniasis (Review). Cochrane Database Syst Rev. 2008(4). doi: 10.1002/14651858.CD005067.pub3.

9. Wall EC, Watson J, Armstrong M, Chiodini PL, Lockwood DN. Epidemiology of imported cutaneous leishmaniasis at the Hospital for Tropical Diseases, London, United Kingdom: use of polymerase chain reaction to identify the species. AmJTrop Med Hyg. 2012;86(1):115-8. doi:10.4269/ajtmh.2012.10-0558.

10. Koltas IS, Eroglu F, Alabaz D, Uzun S. The emergence of Leishmania major and Leishmania donovani in southern Turkey. Trans R Soc Trop Med Hyg. 2014;108(3):154-8. doi:10.1093/trstmh/trt119.

11. Reithinger R, Dujardin JC. Molecular diagnosis of leishmaniasis: current status and future applications. J Clin Microbiol. 2007:45(1):21.

12. Herwaldt BL, Stokes SL, Juranek DD. American cutaneous leishmaniasis in U.S. travelers. Ann Intern Med. 1993:118(10):779-84.

13. Gangneux JP, Menotti J, Lorenzo F, Sarfati C, Blanche H, Bui H, et al. Prospective value of PCR amplification and sequencing for diagnosis and typing of old world Leishmania infections in an area of nonendemicity. J Clin Microbiol. 2003:41(4):1419-22.

14. de Monbrison F, Mihoubi I, Picot S. Real-time PCR assay for the identification of cutaneous Leishmania parasite species in Constantine region of Algeria. Acta Trop. 2007;102(2):79-83. doi:10.1016/j.actatropica. 2007.04.001

15. Ramanathan R, Talaat KR, Fedorko DP, Mahanty S, Nash TE. A species-specific approach to the use of non-antimony treatments for cutaneous leishmaniasis. AmJTrop Med Hyg. 2011;84(1):109-17. doi:10.4269/ajtmh.2011.10-0437.

16. Tomas-Perez M, Fisa R, Riera C. The use of fluorescent fragment length analysis (PCR-FFL) in the direct diagnosis and identification of cutaneous Leishmania species. AmJTrop Med Hyg. 2013;88(3):586-91. doi:10.4269/ ajtmh.12-0402

17. Bousslimi N, Ben-Ayed S, Ben-Abda I, Aoun K, Bouratbine A. Natural infection of North African gundi (Ctenodactylus gundi) by Leishmania tropica in the focus of cutaneous leishmaniasis, Southeast Tunisia. AmJTrop Med Hyg. 2012;86(6):962-5. doi:10.4269/ajtmh.2012.11-0572.

18. Stevenson LG, Fedorko DP, Zelazny AM. An enhanced method for the identification of Leishmania spp. using real-time polymerase chain reaction and sequence analysis of the 7SL RNA gene region. Diagn Microbiol Infect Dis. 2010;66(4):432-5. doi:10.1016/j.diagmicrobio.2009.11.005.

19. Sue MJ, Yeap SK, Omar AR, Tan SW. Application of PCR-ELISA in molecular diagnosis. Biomed Res Int. 2014;2014:653014. doi:10.1155/2014/653014.

20. Wortmann G, Hochberg L, Houng HH, Sweeney C, Zapor M, Aronson N, et al. Rapid identification of Leishmania complexes by a real-time PCR assay. AmJTrop Med Hyg. 2005:73(6):999-1004.

21. Ben Abda I, de Monbrison F, Bousslimi N, Aoun K, Bouratbine A, Picot S. Advantages and limits of real-time PCR assay and PCR-restriction fragment length polymorphism for the identification of cutaneous Leishmania species in Tunisia. Trans R Soc Trop Med Hyg. 2011;105(1):17-22. doi:10.1016/j. trstmh.2010.09.003. 
22. Castilho TM, Camargo LM, McMahon-Pratt D, Shaw JJ, Floeter-Winter LM. A real-time polymerase chain reaction assay for the identification and quantification of American Leishmania species on the basis of glucose-6-phosphate dehydrogenase. AmJTrop Med Hyg. 2008;78(1):122-32.

23. Nicolas L, Milon G, Prina E. Rapid differentiation of Old World Leishmania species by LightCycler polymerase chain reaction and melting curve analysis. J Microbiol Methods. 2002;51(3):295-9.

24. Ceccarelli M, Galluzzi L, Migliazzo A, Magnani M. Detection and characterization of Leishmania (Leishmania) and Leishmania (Viannia) by SYBR green-based real-time PCR and high resolution melt analysis targeting kinetoplast minicircle DNA. PLoS One. 2014;9(2):e88845. doi:10.1371/journal.pone.0088845.

25. Thornton $B$, Basu C. Real-time PCR ( $(P C R$ ) primer design using free online software. Biochem Mol Biol Educ. 2011;39(2):145-54. doi:10.1002/bmb.20461.

26. Tsukayama $P$, Núñez JH, De Los Santos M, Soberon $V$, Lucas CM, Matlashewski G, Llanos-Cuentas A, Ore M, Baldeviano GC, Edgel KA, Lescano AG, Graf PC, Bacon DJ. A FRET-based real-time PCR assay to identify the main causal agents of New World tegumentary leishmaniasis. PLoS Negl Trop Dis. 2013;7(1):e1956.

27. Chaouch M, Fathallah-Mili A, Driss M, Lahmadi R, Ayari C, Guizani I, et al. Identification of Tunisian Leishmania spp. by PCR amplification of cysteine proteinase B (cpb) genes and phylogenetic analysis. Acta Trop. 2013;125(3):357-65. doi:10.1016/j.actatropica.2012.11.012.

28. Sakanari JA, Nadler SA, Chan VJ, Engel JC, Leptak C, Bouvier J. Leishmania major: comparison of the cathepsin L- and B-like cysteine protease genes with those of other trypanosomatids. Exp Parasitol. 1997;85(1):63-76. doi:10.1006/expr.1996.4116.

29. Kuru T, Janusz N, Gadisa E, Gedamu L, Aseffa A. Leishmania aethiopica: development of specific and sensitive PCR diagnostic test. Exp Parasitol. 2011;128:391-5.

30. Laurent T, Van der Auwera G, Hide M, Mertens P, Quispe-Tintaya W, Deborggraeve $S$, et al. Identification of Old World Leishmania spp. by specific polymerase chain reaction amplification of cysteine proteinase $B$ genes and rapid dipstick detection. Diagn Microbiol Infect Dis. 2009;63(2):173-81. doi:10.1016/j.diagmicrobio.2008.10.015

31. Reale S, Maxia L, Vitale F, Glorioso NS, Caracappa S, Vesco G. Detection of Leishmania infantum in dogs by PCR with lymph node aspirates and blood. J Clin Microbiol. 1999;37(9):2931-5.

32. Degrave W, Fernandes O, Campbell D, Bozza M, Lopes U. Use of molecular probes and PCR for detection and typing of Leishmania - a mini-review. Mem Inst Oswaldo Cruz. 1994;89(3):463-9.

33. Ririe KM, Rasmussen RP, Wittwer CT. Product differentiation by analysis of DNA melting curves during the polymerase chain reaction. Anal Biochem. 1997;245(2):154-60. doi:10.1006/abio.1996.9916.

34. Schwenkenbecher JM, Frohlich C, Gehre F, Schnur LF, Schonian G. Evolution and conservation of microsatellite markers for Leishmania tropica. Infect Genet Evol. 2004;4(2):99-105. doi:10.1016/j.meegid.2004.01.005.

35. Krayter L, Alam MZ, Rhajaoui M, Schnur LF, Schonian G. Multilocus Microsatellite Typing reveals intra-focal genetic diversity among strains of Leishmania tropica in Chichaoua Province, Morocco. Infect Genet Evol. 2014;28:233-9. doi:10.1016/j.meegid.2014.09.037.

36. Wittwer CT, Reed GH, Gundry CN, Vandersteen JG, Pryor RJ. High-resolution genotyping by amplicon melting analysis using LCGreen. Clin Chem. 2003;49(6.1):853-60

37. Monis PTGS, Saint CP. Comparison of SYTO9 and SYBR Green I for real-time polymerase chain reaction and investigation of the effect of dye concentration on amplification and DNA melting curve analysis. Anal Biochem. 2005;340:24-34.

38. Robinson BSMP, Dobson PJ. Rapid, sensitive, and discriminating identification of Naegleria spp. by real-time PCR and melting-curve analysis. Appl Environ Microbiol. 2006;72:5857-63.

39. Talmi-Frank D, Nasereddin A, Schnur LF, Schonian G, Toz SO, Jaffe CL, et al. Detection and identification of old world Leishmania by high resolution melt analysis. PLoS Negl Trop Dis. 2010;4(1):e581. doi:10.1371/journal. pntd.0000581.

40. Yamasaki H, Agatsuma T, Pavon B, Moran M, Furuya M, Aoki T. Leishmania major-like parasite, a pathogenic agent of cutaneous leishmaniasis in Paraguay. AmJTrop Med Hyg. 1994;51(6):749-57.

41. Silva Sde O, Wu AA, Evans DA, Vieira LQ, Melo MN. Leishmania sp. isolated from human cases of cutaneous leishmaniasis in Brazil characterized as Leishmania major-like. Acta Trop. 2009;112(3):239-48. doi:10.1016/j. actatropica.2009.07.026.
42. Weirather JL, Jeronimo SM, Gautam S, Sundar S, Kang M, Kurtz MA, Haque R, Schriefer A, Talhari S, Carvalho EM, Donelson JE, Wilson ME. Serial quantitative PCR assay for detection, species discrimination, and quantification of Leishmania spp. in human samples. J Clin Microbiol. 2011;3892-904

43. Luc Nicolas EP. Thierry Lang, and Geneviève Milon. Real-Time PCR for detection and quantitation of Leishmania in mouse tissues. J Clin Microbiol. 2002:40(5):1666-9.

44. Lea Hosnjak BJK, Kusar B, Seme K, Poljak M. Rapid detection and typing of Molluscum contagiosum virus by FRET-based real-time PCR. J Virol Methods. 2013:187:431-4

45. Kelly Wilber Quispe-Tintaya TL, Decuypere S, Hide M, Banuls A-L, De Doncker S, Rijal S, Canavate C, Campino L, Dujardin J-C. Fluorogenic assay for molecular typing of the Leishmania donovani complex: Taxonomic and clinical applications. J Infect Dis. 2005;192:685-92.

46. Alexandra Schulz KM, Schonian G, Fleischer B, Drosten C. Detection, differentiation, and quantitation of pathogenic Leishmania organisms by a fluorescence resonance energy transfer-based real-time PCR assay. J Clin Microbiol. 2003;41(4):1529-35.

47. Rasmussen JP, Saint CP, Monis PT. Use of DNA melting simulation software for in silico diagnostic assay design: targeting regions with complex melting curves and confirmation by real-time PCR using intercalating dyes. BMC Bioinformatics. 2007;8:107. doi:10.1186/1471-2105-8-107.

48. Foulet F, Botterel F, Buffet $P$, Morizot $G$, Rivollet $D$, Deniau M, et al. Detection and identification of Leishmania species from clinical specimens by using a real-time PCR assay and sequencing of the cytochrome $B$ gene. J Clin Microbiol. 2007;45(7):2110-5. doi:10.1128/jcm.02555-06.

49. Antinori S, Calattini S, Piolini R, Longhi E, Bestetti $G$, Cascio A, et al. Is real-time polymerase chain reaction (PCR) more useful than a conventional PCR for the clinical management of leishmaniasis? AmJTrop Med Hyg. 2009;81(1):46-51.

50. Garcia AL, Kindt AK, Quispe-Tintaya KW, Bermudez L, Arevalo J, Banuls AL, De Doncker S, Le R, Dujardin JC. American tegumentary leishmaniasis: antigen-gene polymorphism, taxonomy and clinical pleomorphism. Infect Genet Evol. 2005;5:109-16.

51. Quispe Tintaya KW, Ying X, Dedet JP, Rijal S, De Bolle X, Dujardin JC. Antigen genes for molecular epidemiology of leishmaniasis: polymorphism of cysteine proteinase B and surface metalloprotease glycoprotein 63 in the Leishmania donovani complex. J Infect Dis. 2004;189:1035-43.

52. Hide $M$, Bañuls $A-L$. Species-specific $P C R$ assay for $L$. infantum/L. donovani discrimination. Acta Trop. 2006;100(3):241-5. http://dx.doi.org/10.1016/j. actatropica.2006.10.012.

\section{Submit your next manuscript to BioMed Central and we will help you at every step:}

- We accept pre-submission inquiries

- Our selector tool helps you to find the most relevant journal

- We provide round the clock customer support

- Convenient online submission

- Thorough peer review

- Inclusion in PubMed and all major indexing services

- Maximum visibility for your research

Submit your manuscript at www.biomedcentral.com/submit
Ciomed Central 